\title{
Geometric documentation of underwater archaeological sites
}

\author{
Eleni Diamanti ${ }^{1}$, Andreas Georgopoulos ${ }^{1}$, Fotini Vlachaki ${ }^{2}$ \\ ${ }^{1}$ Laboratory of Photogrammetry, National Technical University of Athens \\ drag@central.ntua.gr \\ ${ }^{2}$ Hellenic Institute of Marine Archaeology \\ ienae@otenet.gr
}

\begin{abstract}
Photogrammetry has often been the most preferable method for the geometric documentation of monuments, especially in cases of highly complex objects, of high accuracy and quality requirements and, of course, budget, time or accessibility limitations. Such limitations, requirements and complexities are undoubtedly features of the highly challenging task of surveying an underwater archaeological site. This paper is focused on the case of a Hellenistic shipwreck found in Greece at the Southern Euboean gulf, 40-47 meters below the sea surface. Underwater photogrammetry was chosen as the ideal solution for the detailed and accurate mapping of a shipwreck located in an environment with limited accessibility. There are time limitations when diving at these depths so it is essential that the data collection time is kept as short as possible. This makes custom surveying techniques rather impossible to apply. However, with the growing use of consumer cameras and photogrammetric software, this application is becoming easier, thus benefiting a wide variety of underwater sites. Utilizing cameras for underwater photogrammetry though, poses some crucial modeling problems, due to the refraction effect and further additional parameters which have to be co-estimated [1]. The applied method involved an underwater calibration of the camera as well as conventional field survey measurements in order to establish a reference frame. The application of a three-dimensional trilateration using common tape measures was chosen for this reason. Among the software that was used for surveying and photogrammetry processing, were Site Recorder SE, Eos Systems Photomodeler, ZI's SSK and Rhinoceros. The underwater archaeological research at the Southern Euboean gulf is a continuing project carried out by the Hellenic Institute for Marine Archaeology (H.I.M.A.) in collaboration with the Greek Ephorate of Underwater Antiquities, under the direction of the archaeologist G.Koutsouflakis. The geometric documentation of the shipwreck was the result of the collaboration between H.I.M.A. and the National Technical University of Athens.
\end{abstract}

Keywords: underwater photogrammetry, trilateration, underwater camera calibration, visualization, orthophotomosaics, 3D reconstruction, ancient shipwreck

\section{Introduction}

With 17,000 kilometers of coastline, equivalent to $25 \%$ of the total Mediterranean coast, with almost 3,500 islands and at least 1,000 shipwrecks detected in the Greek seas, Greece is a country with one of the largest and perhaps the most important underwater archaeological 
heritage. Ancient shipwrecks, submerged settlements or ancient harbors are housed for centuries in the Greek seas. Nevertheless, practical implication of theoretical and technological developments in the fields of surveying and photogrammetry for the geometric documentation of this underwater heritage is far behind the rapid developments and innovations that are applied when it comes to surveying 'terrestrial' monuments. This paper presents an effort to improve and experiment on the synergy of conventional surveying techniques, such as simple tape measurements and trilateration adjustments, with modern software and digital technology, in order to produce 3 dimensional reconstructions that can assist underwater archaeologists in reaching their scientific conclusions, through a geometrically accurate, documentation of the site and the excavation process, as well as to bring those who do not have the opportunity to access this submerged monument, on a 'digital trip' to an ancient shipwreck in deep waters.

\subsection{Description of the object}

The Hellenistic shipwreck, whose case is examined in this paper, was found in 2006 in the northwest side of the island Styronisi at Southern Euboean gulf, at a depth range of depth between 39 and 47 meters below the sea surface. The shipwreck dates back to the Late Hellenistic period (late 2nd to early half of the 1st century B.C.) and it is the only ancient shipwreck that was detected in Southern Euboean gulf, in such a relatively good condition. The dimensions of the exposed shipwreck are approximately 18 meters long and 7 meters wide. The cargo of the ship consists, mainly, of intact and broken amphorae, $90 \%$ of which are considered as Brindisi type of amphorae. Additionally, among the ship's cargo interesting objects were found, such as parts of luxurious bronze furniture, bronze and steel spikes, a stone wash basin, parts of the harness of the ship and broken tiles. Among the most important finds of the whole archaeological survey, is a small part of the dress of a natural size bronze statue and beneath the surface layer of sand, two parts of the wooden hull of the vessel, something very rare, since wood cannot be preserved for such a long time in underwater archaeological sites.

Since the discovery of the specific wreck is considered of great importance, H.I.M.A. and the supervising archaeologist intended to launch a systematic investigation and excavation of this monument. Therefore, the detailed and accurate documentation of the site became an immediate priority. Orthophotomosaics and 3D rendered models of the wreck were considered as the ideal products, in order to map the site in the condition that it was found and prior to excavation [2]. Of course, when it comes to the excavation period, the requirements are increasing; daily recording of the excavation trenches, mapping of the 3D locations of the artifacts, 3D reconstruction of the shipwreck excavation, production of daily 2D plans or 3D measurement and modelling of finds are some of the needs that arise for the complete documentation of such a monument.

\subsection{Underwater surveying \& underwater photogrammetry}

It is well-known that conventional mapping is a process subject to human error in underwater archaeology $[3,4,5]$, while photogrammetry has long been a viable technique in such situations [6]. Thus the main objective is to create a 3-dimensional model of the site using photogrammetry, which could be dynamically updated in the future according to the progress of the ongoing archaeological excavation. Underwater photogrammetry clearly offers 
some advantages for the surveying of a submerged site thus overcoming difficulties such as limited on-site accessibility and non-destructive efficiency. On the other hand, some crucial and inevitable matters that have to be faced and co-estimated arise in such conditions: no operational control on data acquisition, low image quality caused by poor underwater lighting (e.g. variations of scattering or absorption of red wavelength especially in deep waters) even if artificial lighting is used, two-media (air-water) data collection, , significant diffusion that complicates the object recognition and the tie point measurements and, last but not least, control point establishment limitations as common tape measurements and 3D trilateration methods are perhaps the only plausible methods. Despite all the difficulties encountered, photogrammetric software can be increasingly extended from land-based applications to underwater applications.

\section{The geometric documentation of the hellenistic shipwreck in south Euboea}

\subsection{Establishing an underwater control points network}

One of the main tasks of the surveying procedure on site was to establish an underwater network of control points, which would be measured and calculated with tape trilateration adjustment. Once the theoretical control network had been designed in terms of adequate geometry, i.e. widely dispersed control points and efficient stability of the points, it had to be set up on the site. It is at this point, where the problems associated with surveying under water start to affect the quality of the survey. The tape survey is dependent on the divers' ability to install control points in geometrically correct positions of high rigidness, as well as to measure the distances between the points with sufficient accuracy. In this case, 20 control points were established. They were made of targets stuck on $10 \times 10 \mathrm{~cm} 2$ Plexiglas tiles; fourteen of them, fitted onto $0.5 \mathrm{~m}$ long metal rods, were inserted in sand as deep as possible (Fig.1a) and the remaining six were fitted, with common tie-wraps, on the mouths of 6 intact amphorae (Fig.1b). The tiles bearing the target points were also labeled with numbers, so that they could be easily identified by the divers.
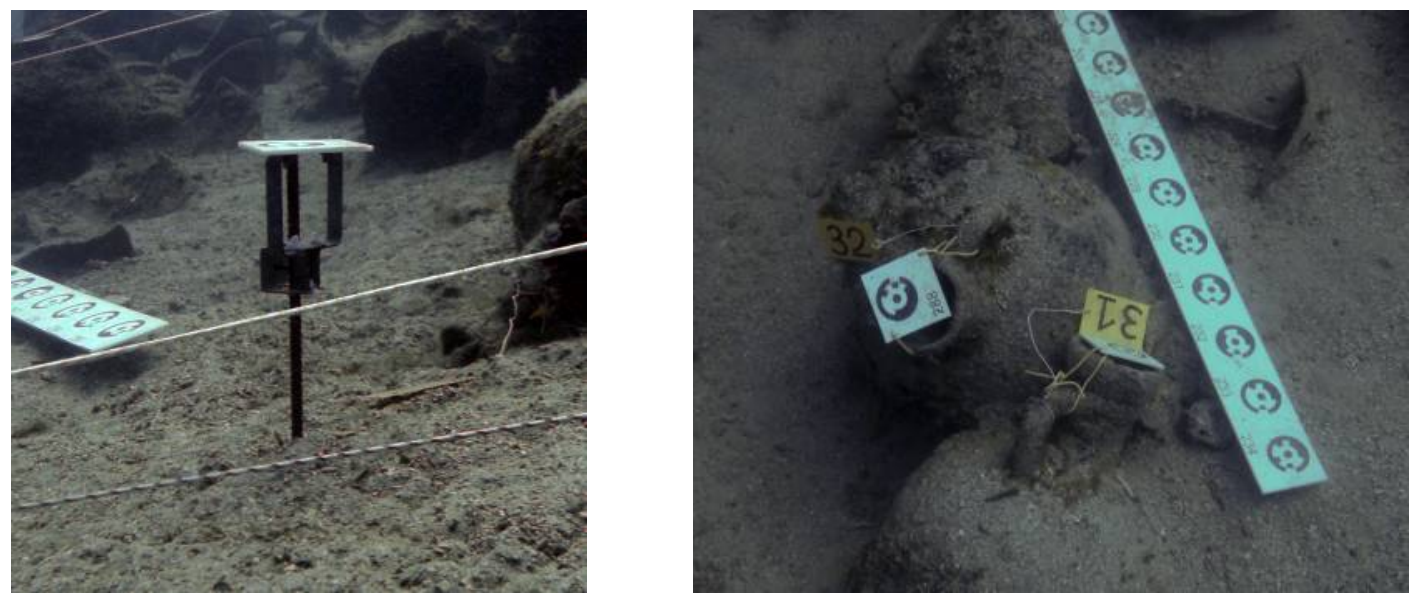

Figure 1: (a) Control points inserted in sand, (b) Control points fitted on the mouth of amphorae

The position of each control point was measured from at least 5 other control points of the 
network. From a total number of 119 measured distances, 82 were selected and adjusted using the Site Recorder SE software through a large least-squares network adjustment. In order to obtain three-dimensional coordinates for a point, the minimum number of measurements is of course three. With three measurements, error or reliability cannot be estimated. Therefore, at least 5 measurements from each point were taken, so that the accuracy of the coordinates of each control point could be estimated. The total RMS of the trilateration adjustment resulted to $0.027 \mathrm{~m}$.

\subsection{Data acquisition}

For the optimal organization of the photogrammetric restitution, a photomosaic of the shipwreck was created as an approximate complete mapping of the site. The Hugin open source software, a piece of software typically used for stitching and blending a series of photographs was employed. This software was developed by B. Hartzler, an archaeologist and member of H.I.M.A. [7]. This first photomosaic proved to be a very useful tool for the photogrammetric image data acquisition that followed.

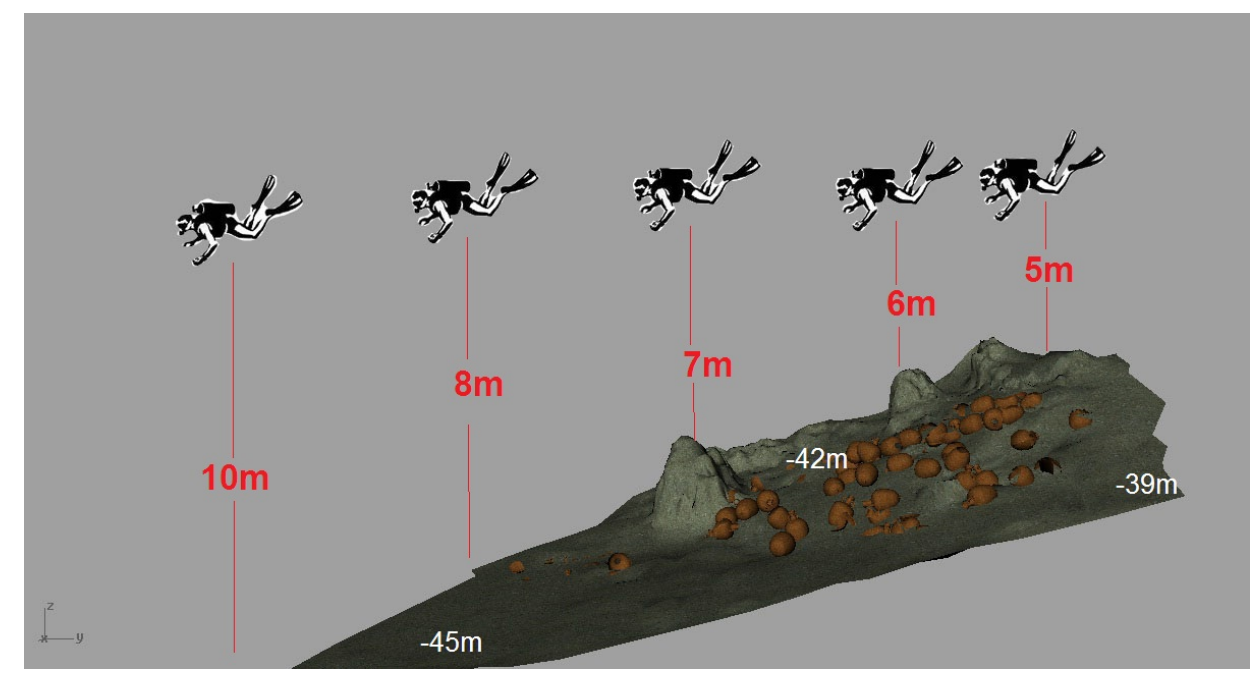

Figure 2: Photo data capture

For the image data acquisition, a SONY DSLR-A700 camera and an Ikelite ${ }^{\circledR}$ protecting housing were available. The camera has a $12-\mathrm{mm}$ lens and all individual images are of a resolution of $4272 \times 2848$ pixels. The diver-photographer "flew" over the wreck (Figure 2), taking about 120 photos in 4 strips, with a $70-80 \%$ forward overlap and $50 \%$ side overlap. The physics of underwater light diffusion requires that images should be taken as close to the object as possible. Images taken from longer distances have, as a result, much lower quality. A standard "flying height", a strictly straight strip line and a satisfying overlap between images are definitely requirements of an optimal data acquisition for photogrammetric processing purposes. Nevertheless, it seems to be a really challenging task when photographing under such conditions. In this case, the limited available time of the archaeological research, the increased difficulty to approach the site and the strong underwater currents did not favor the image acquisition process with the aforementioned requirements. 


\section{Photogrammetric processing}

\subsection{Underwater camera calibration}

The accurate 3D reconstruction, as well as the pose estimation of an object, from images, requires the thorough knowledge of the intrinsic camera parameters i.e. focal length, principal point's coordinates and lens distortion. The underwater camera calibration problem has been treated in several ways so far. A 'standard case' of multimedia photogrammetry [8]: three media; an object in water, a sensor located in air and a transparent plane of the camera housing separating the object from the sensor. As far as using images for underwater surveying is concerned, there are generally two categories for approaching camera calibration; the first is based on dry camera calibration methods, where the intrinsic parameters of a camera immersed in water, or any other fluid, can be calculated from an air calibration, as long as the optical surface between the two fluids presents some simple geometrical properties [9]. The second approach, is not based on modeling any parameters that have to do with different media through mathematical models, but treats the system camera-housing (or airglass-water) as a unique system.

The camera calibration in this project's case is based on the second approach and was carried out using the Photomodeler® calibration module. A SONY DSLR A700 camera, in a waterproof Ikelite housing device, was immersed into water and a total number of 24 images of the board bearing the calibration pattern, i.e. a grid of specific dots (Figures 3a, b, c) were taken. Photomodeler, firstly, analyses each picture using a line interpolation algorithm to find and mark the dots and the 4 control points of the plane pattern [10]. Seventeen (17) images were processed into an image processing software in such a way that the algorithm could detect only the coded dots-targets (Figure 3b). The scale was constrained by the 4 known distances between the control points of the pattern.
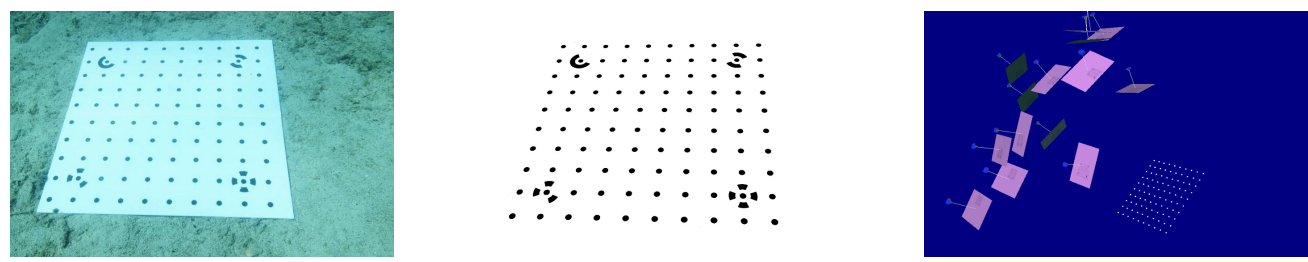

Figure 3: (a) Initial calibration image, (b) Corrected calibration image, (c) Camera positions.

On completion of the calibration, the intrinsic parameters of the camera were determined, including the principal point's coordinates, the radial distortion values and a focal length of $15.03 \mathrm{~mm}$. As far as the focal length is concerned, the ratio computed-to-nominal value $(15,03 \mathrm{~mm} / 13 \mathrm{~mm})$ was found to be 1.16 . When compared to the refractive index (1.34), it is obvious that underwater refraction is not the only parameter that has to be estimated, contrary to the dry camera calibration procedures. Depth, temperature and salinity can be considered as unstable parameters affecting a typical photogrammetric camera calibration. In comparison to the refractive index, there are no mathematical models that can describe these parameters, thus not permitting the achievement of a reliable camera calibration procedure. Eventually, it would be desirable, given an unrestricted underwater time, if a camera calibration could be completed in identical conditions to each archaeological photogrammetric dive.

Geoinformatics FCE CTU 11, 2013 


\subsection{Photogrammetric bundle adjustment}

A matter of high importance is to have the acquired images prerectified before using them in the photogrammetric processing [11]. Preprocessing adjustments include radiometric enhancement of images, i.e. brightness adjustment, contrast enhancement, edge enhancement, noise reduction etc. Therefore, 46 images were selected and processed using Adobe Photoshop software, through 'Neutralize', 'Brightness-Contrast' and 'Color balance' commands (Figures $4 \mathrm{a}$ and $4 \mathrm{~b})$.
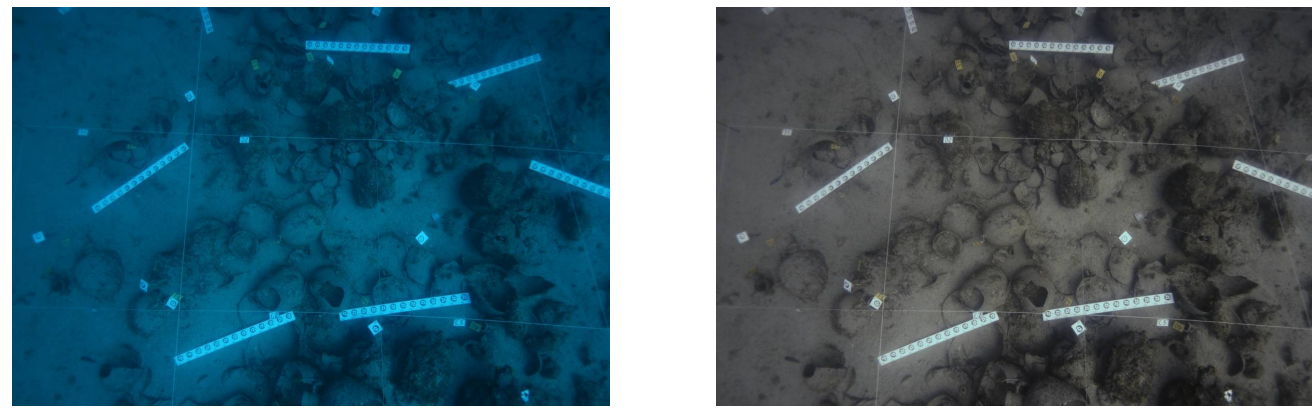

Figure 4: (a) Initial image, (b) Color processed image

Once all 46 images were preprocessed, the photogrammetric adjustment was implemented using Topcon's ImageStation ${ }^{\circledR}$ software. The block adjustment was done using 46 images at an approximate range of scale from 1:200 to 1:600, as the diver-photographer could not swim parallel to the site. Twenty (20) points with known coordinates, as resulted from the trilateration adjustment method with Site Recorder, were recognized, marked on the images and utilized as control points. The a priori control point precision was set at $\sigma_{X Y}=0.04 \mathrm{~m}$ and $\sigma_{Z}=0.07 \mathrm{~m}$. Table 1 shows the results of the bundle adjustment.

Table 1: Bundle adjustment results

\begin{tabular}{|c|c|}
\hline RMSxy $(\mu \mathrm{m})$ & 6.2 \\
\hline Pixel size $(\mu \mathrm{m})$ & 5.8 \\
\hline RMSXY $(\mathrm{m})$ & 0.025 \\
\hline RMSZ $(\mathrm{m})$ & 0.037 \\
\hline
\end{tabular}

A fact which has to be stressed is that the block included images of regions of sandy seabed. This was a problem, as far as finding a sufficient number of common points between images, is concerned. To increase the number of common points, Plexiglas strips with coded targets, similar to Photomodeler ${ }^{\circledR}$ calibration targets, were positioned in those sandy areas. This method proved to be very helpful in the end, in the attempt to evaluate the accuracy of the final orthophotomosaic of the site, especially in sandy areas where the control point distribution could not be very dense.

\subsection{Orthophotomosaic of the shipwreck}

One of the main goals of the work was to produce an accurate and radiometrically correct orthophotomosaic of the entire area of the shipwreck. Therefore, once the photogrammetric bundle adjustment of the block was completed, the extraction of a Digital Surface Model 


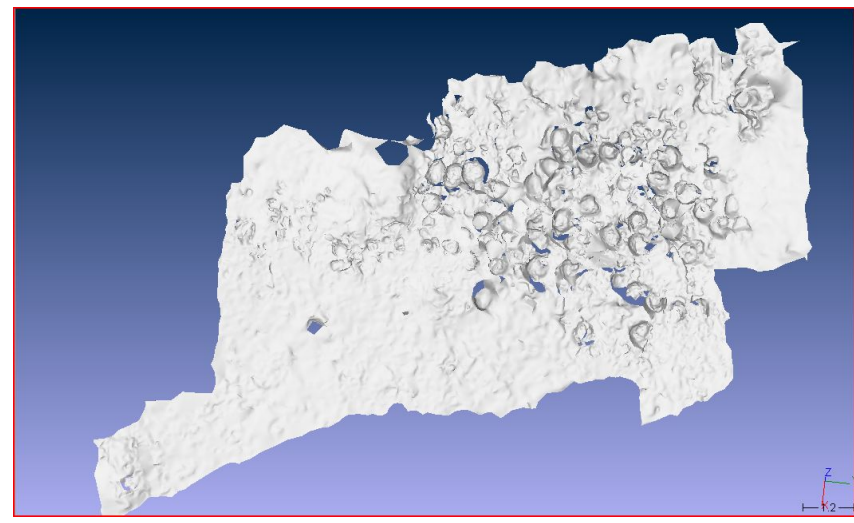

Figure 5: Digital Surface Model of the site

was initiated. Approximately 54000 points and 2000 break lines were collected manually through stereoscopic vision of the oriented models, thus producing a dense DSM (Figure 5). The attempt for automated DSM extraction failed, due mainly to problems connected with a weak image radiometry, e.g. similar tones especially due to the absorption of the red wavelength, repetitive features and poor textures like sandy areas, scale variations and large rotation differences between images and, finally, occlusions. As a result, the acquired data did not reach the classical image matching methods standards and a manual DSM extraction was the only solution.

Once the DSM was extracted, an orthophotomosaic of the shipwreck's area, made out of 46 orthorectified images (Figure 6), was produced using Z/I's ImageStation OrthoPro® software. The final product was evaluated in two ways:

1. By comparing the control points network, as it resulted from the trilateration adjustment, with the orthophotomosaic

2. By measuring on the orthophotomosaic the known distances between the Plexiglas strips of Photomodeler coded targets.

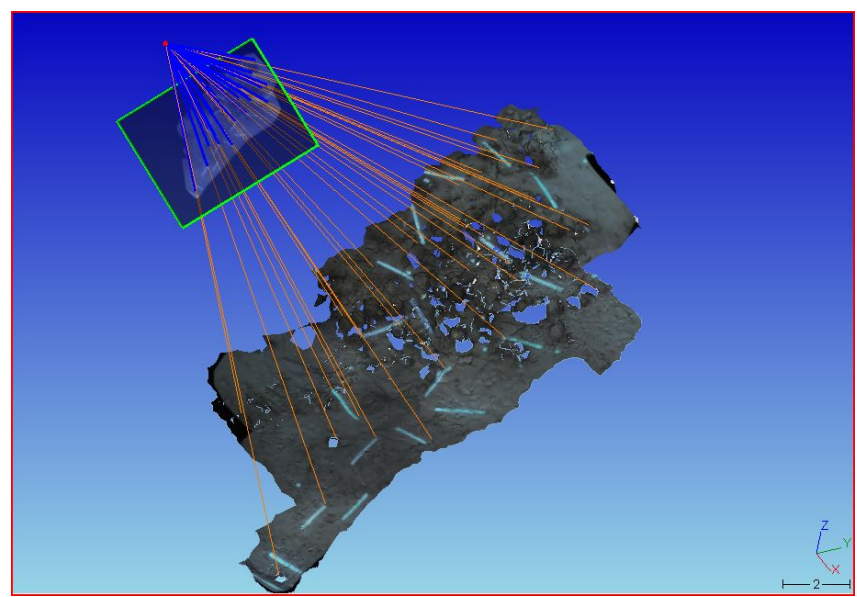

Figure 6: Orthophoto mapping of the shipwreck's area with the use of DSM 

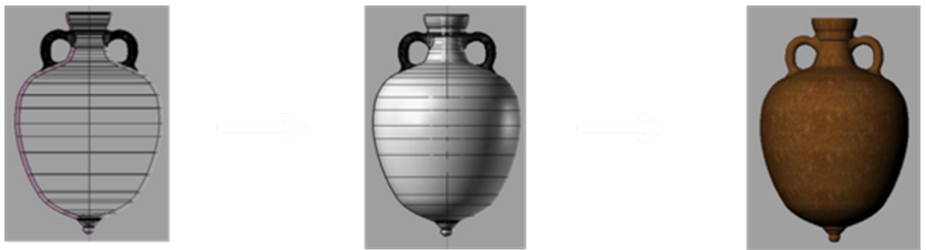

Figure 7: (a) 2D scaled drawing of a Brindisi amphora, (b) 3D revolved amphorae model, (c) $3 \mathrm{D}$ rendered model

\section{4. $3 \mathrm{D}$ reconstruction of the shipwreck}

The ship's cargo consisted mainly of amphorae of one type, i.e. Brindisi amphorae. A 3D theoretical revolved model was obtained using 2D scaled drawing of one such amphora, which was taken off the site using the Rhinoceros ${ }^{\circledR}$ software (Figures $7 \mathrm{a}, 7 \mathrm{~b}$ and $7 \mathrm{c}$ ).

Due to the fact that most of the objects were partially visible on images or even broken, photogrammetric measurements were not enough for the complete 3D reconstruction of the site. The main reason for not using the already constructed and dense DSM for plotting each object is that it is a $2.5 \mathrm{D}$ plan. This means that many objects' attributes were not visible on images, thus hiding an important amount of information. Therefore, characteristic features of each object were photogrammetrically measured, so that accurate shape, size and direction of the amphorae could be restored. The final 3D model is a combination of the theoretical models and the photogrammetrically measured attributes of the various finds (Figure 8). The choice of attributes is based on measuring particular parts of the finds, i.e. rims, bodies, mouths or handles of each amphora, so that each object could be positioned as well as oriented efficiently. The photogrammetric measuring of those attributes was performed using Photomodeler ${ }^{\circledR}$ software, in which approximately 60 images were oriented. Photomodeler provides the opportunity of orienting a large number of images taken from various angles, thus regaining the lost information of hidden objects that led to the optimal 3D reconstruction of the site. Measured objects were divided into three layers in Photomodeler; a) the 'terrain' layer, which plays the role of a DTM and consists of points of sand and rocks, b) the 'finds' layer, which includes all measured attributes of finds and c) the 'control points' layer, which includes the control points network.
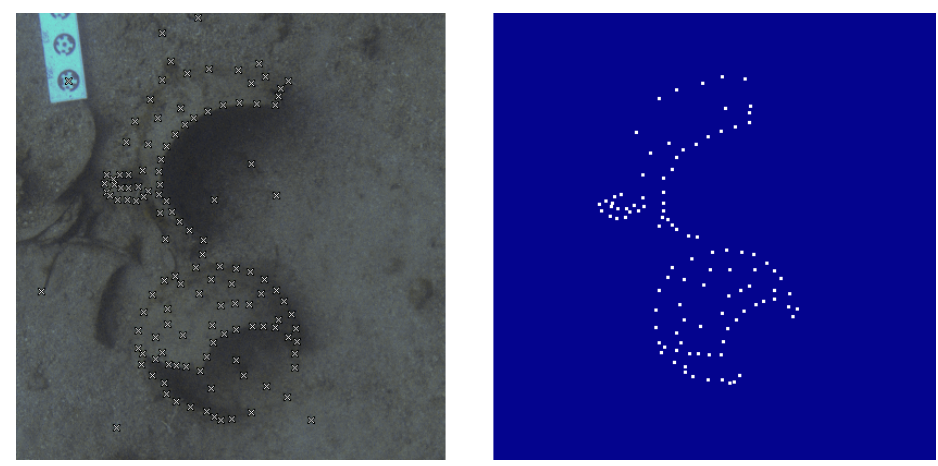

Figure 8: Measured attributes of the artifacts

A DXF file of points of the above layers, followed by images with the IDs of all points of interest 
upon (Figure 8), was extracted from Photomodeler® and then imported in Rhinoceros ${ }^{\circledR}$. The entire 3D reconstruction of the site was implemented finally in Rhinoceros ${ }^{\circledR}$ by creating the terrain surface at first and placing, afterwards, each find in its right position (Figure 9).

A more realistic representation of the site was achieved by assigning texture extracted from images through a suitable rendering procedure (Figure 10). The rendering was implemented in Autodesk's 3DS max®.

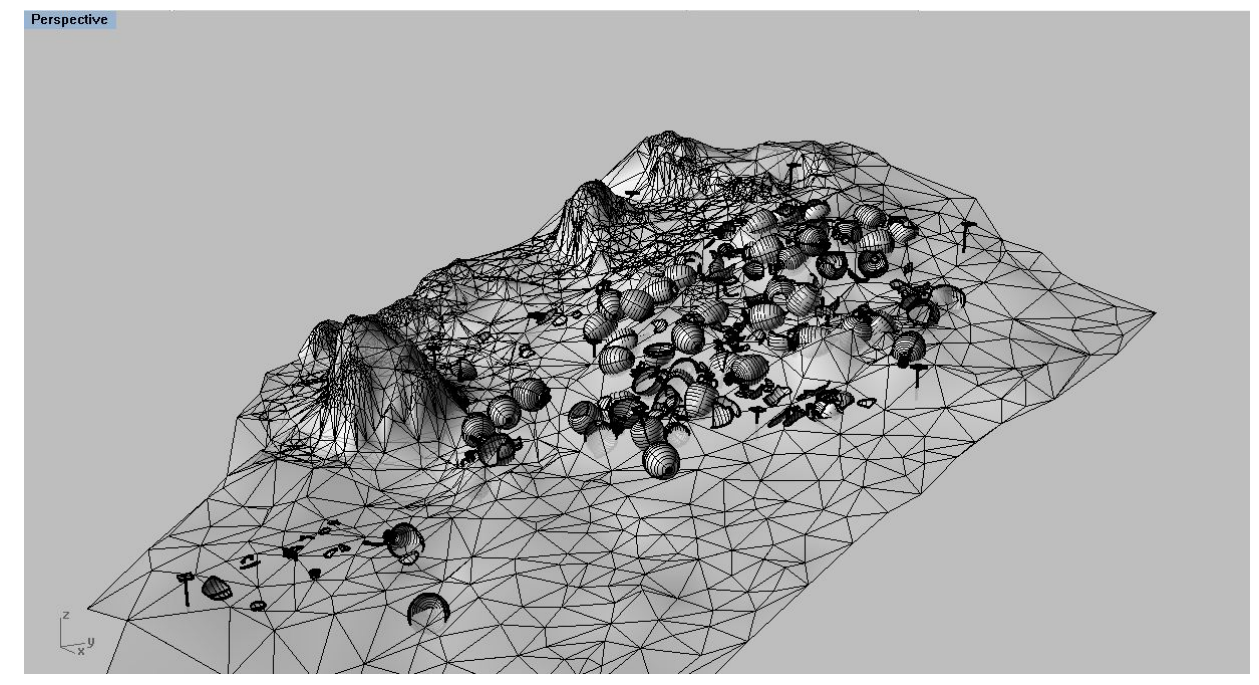

Figure 9: 3D wireframe model of the shipwreck

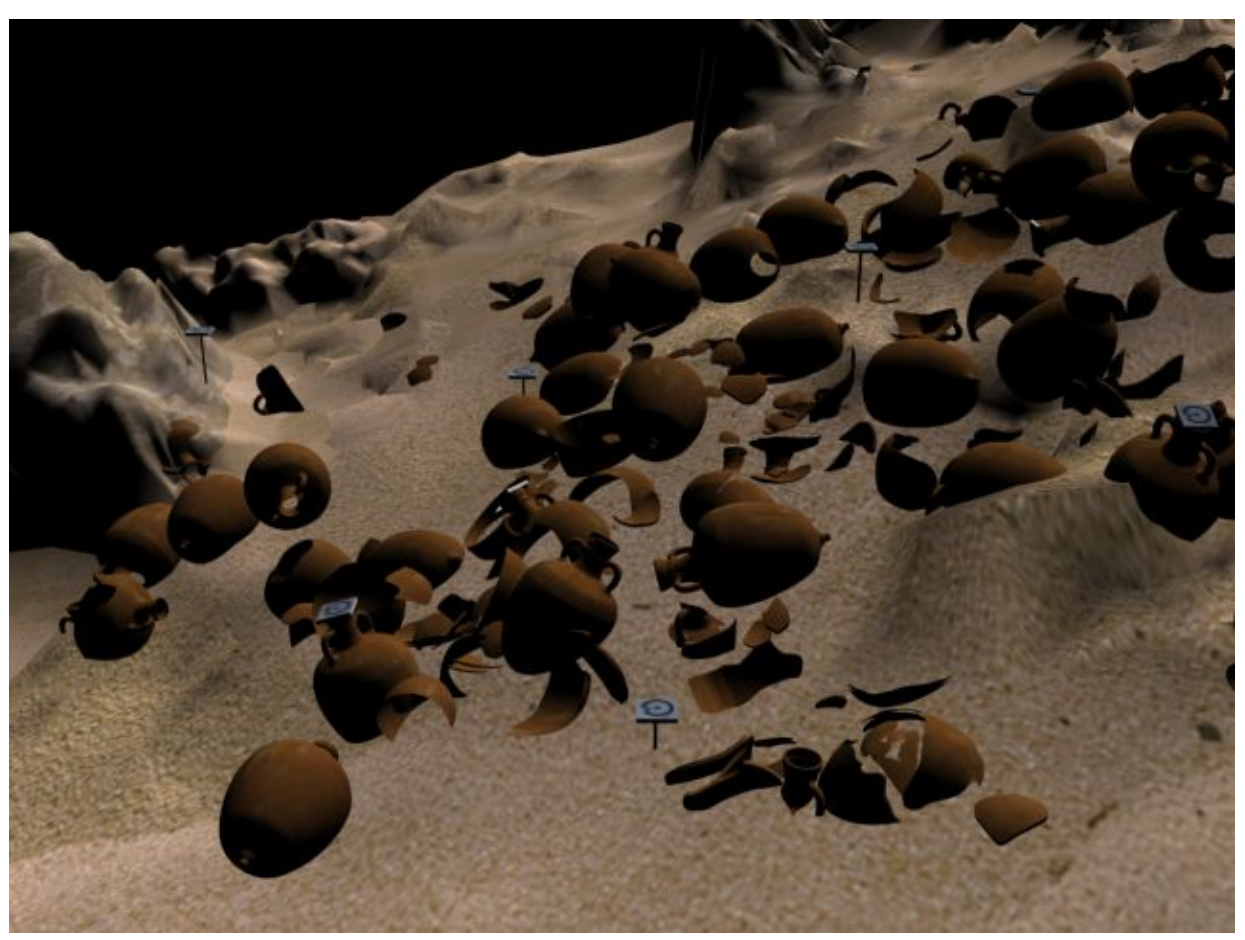

Figure 10: 3D rendered model of the shipwreck, Autodesk 3DS max 


\section{Conclusions}

Estimating the accuracy of any underwater surveying technique is notoriously difficult [12]. The results of recording the shipwreck of the South Euboean gulf represent an attempt for the best possible achievable accuracy, when combining conventional tape measurements with modern and user-friendly photogrammetric software. Given the nature of the control points (some robust, others more fragile), it is likely that the points themselves had an uncertainty in their position, which affected the accuracy of the photogrammetric bundle adjustment. Therefore, the task of obtaining a robust control points' network seems as challenging as the task of using photogrammetry for underwater surveying without establishing a control points' network at all. The second task requires a perfectly calibrated camera and a way to restore the scale during the bundle adjustment of a block of images. Evaluating, finally, the work that has been done underwater, given the aforementioned available diving time, it seems that it should be preferable to consume more diving time on calibrating cameras under several conditions underwater, in order to obtain an optimal interior orientation and avoid to spend time on the really time consuming task of measuring distances with common tapes.

Moreover, the implementation of different software for one final goal may be over consuming too, in terms of time and work, but in this case, it was unavoidable to use several pieces of photogrammetric software. Each one was used as a different tool. Photomodeler, provides, firstly, the opportunity of a user-friendly automated camera calibration module and secondly, the opportunity of orienting a large amount of images taken from different angles, so that more information of the object could be obtained. On the other hand, ImageStation software was chosen as a more reliable way, comparing to Photomodeler®, to create a DSM and an orthophoto, thanks to the DSM collection through stereo vision.

In conclusion, the application of photogrammetry in terms of generating accurate and radiometrically efficient orthophotomosaics and 3D rendered models, combining inescapable traditional surveying techniques with contemporary digital software support, has proven to be a unique way to achieve a virtual exploration, a "digital trip", to an ancient shipwreck in deep waters, to a deep ancient cultural heritage.

\section{References}

[1] Gili Telem, Sagi Filin, Photogrammetric modeling of underwater environments, ISPRS Journal of Photogrammetry and Remote Sensing, 2010.

[2] Scarlatos D., Agapiou A., Rova M., Photogrammetric support on an underwater archaeological excavation site: The Mazotos shipwreck case, Cyprus, 2010.

[3] Canciani, M., Gambogi, P., Romano, G., Cannata, G., and Drap, P., 2002, Low cost digital photogrammetry for underwater archaeological site survey and artefact insertion. The case study of the Dolia Wreck in Secche della Meloria, Livorno, Italia, International Archives of Photogrammetry, Remote Sensing and Spatial Information Sciences 34.5/W12, 95-100.

[4] Holt, P., 2003, An assessment of quality in underwater archaeological surveys using tape measurements, IJNA 32.2, 246-51. 
[5] Patias, P., 2006, Cultural Heritage Documentation. International Summer School 'Digital recording and 3D Modeling', Aghios Nikolaos, Crete, Greece, 24-29 April, www.photogrammetry.ethz.ch/summerschool/pdf/15_2_Patias_CHD.pdf, last updated 17 April 2006, accessed 27 July 2009.

[6] Drap P., Durand A., Provin R., Long L., Integration of multi-source spatial information and XML information system in underwater archaeology, Torino, 2005.

[7] Demesticha, S., The 4th-Century-BC Mazotos Shipwreck, Cyprus: A preliminary report, The International Journal of Nautical Archaeology, in press, 2010.

[8] Maas H., New developments in Multimedia Photogrammetry, Institute of Geodesy and Photogrammetry, Swiss Federal Institute of Technology, Zurich, 2000.

[9] Lavest J.M., Rivers G., and Lapreste J.T., Dry camera calibration for underwater applications, Machine Vision and Applications 13, pp. 245-253, 2003.

[10] Walford A., Personal communication Eos Systems Inc, Vancouver, 1996.

[11] Li R., Li H., Zou W., Smith R.G., and Curran T.A., Quantitative photogrammetric analysis of digital underwater video imagery, IEEE Journal of Oceanic Engineering, 22(2) : 364-375, 1997.

[12] Green J., Matthews S., Turanli T., Underwater archaeological surveying using PhotoModeler, VirtualMapper: different applications for different problems, The Nautical Archaeology Society, 2002. 
